\title{
The misdiagnosis of prolonged disorders of consciousness by a clinical consensus compared with repeated coma-recovery scale-revised assessment
}

\author{
Jing Wang ${ }^{1 *} \mathbb{D}$, Xiaohua Hu², Zhouyao Hu' , Ziwei Sun ${ }^{1}$, Steven Laureys ${ }^{3}$ and Haibo Di ${ }^{1^{*}}$
}

\begin{abstract}
Background: Previous studies have shown that a single Coma-Recovery Scale-Revision (CRS-R) assessment can identify high rates of misdiagnosis by clinical consensus. The aim of this study was to investigate the proportion of misdiagnosis by clinical consensus compared to repeated behavior-scale assessments in patients with prolonged disorders of consciousness (DOC).

Methods: Patients with prolonged DOC during hospitalization were screened by clinicians, and the clinicians formed a clinical-consensus diagnosis. Trained professionals used the CRS-R to evaluate the consciousness levels of the enrolled patients repeatedly ( $\geq 5$ times) within a week. Based on the repeated evaluation results, the enrolled patients with prolonged DOC were divided into unresponsive wakefulness syndrome (UWS), minimally conscious state (MCS), and emergence from MCS (EMCS). Finally, the relationship between the results of the CRS-R and the clinical consensus were analyzed.
\end{abstract}

Results: In this study, 137 patients with a clinical-consensus diagnosis of prolonged DOC were enrolled. It was found that $24.7 \%$ of patients with clinical UWS were actually in MCS after a single CRS-R behavior evaluation, while the repeated CRS-R evaluation results showed that the proportion of misdiagnosis of MCS was 38.2\%. A total of $16.7 \%$ of EMCS patients were misdiagnosed with clinical MCS, and 1.1\% of EMCS patients were misdiagnosed with clinical UWS.

Conclusions: The rate of the misdiagnosis by clinical consensus is still relatively high. Therefore, clinicians should be aware of the importance of the bedside CRS-R behavior assessment and should apply the CRS-R tool in daily procedures.

Trial registration: ClinicalTrials.gov ID: NCT04139239; Registered 24 October 2019 - Retrospectively registered.

Keywords: Coma-recovery scale-revised, Disorders of consciousness, Unresponsive wakefulness syndrome, Minimally conscious state, Misdiagnosis

\footnotetext{
*Correspondence: wangjingwyl@aliyun.com; dihaibo19@aliyun.com

${ }^{1}$ International Unresponsive Wakefulness Syndrome and Consciousness Science Institute, Hangzhou Normal University, Hangzhou 310036, China

Full list of author information is available at the end of the article
}

(c) The Author(s). 2020 Open Access This article is licensed under a Creative Commons Attribution 4.0 International License, which permits use, sharing, adaptation, distribution and reproduction in any medium or format, as long as you give appropriate credit to the original author(s) and the source, provide a link to the Creative Commons licence, and indicate if changes were made. The images or other third party material in this article are included in the article's Creative Commons licence, unless indicated otherwise in a credit line to the material. If material is not included in the article's Creative Commons licence and your intended use is not permitted by statutory regulation or exceeds the permitted use, you will need to obtain permission directly from the copyright holder. To view a copy of this licence, visit http://creativecommons.org/licenses/by/4.0/. The Creative Commons Public Domain Dedication waiver (http://creativecommons.org/publicdomain/zero/1.0/) applies to the data made available in this article, unless otherwise stated in a credit line to the data. 


\section{Background}

The most severe injuries result in prolonged (i.e., lasting at least 28 days) disorders of consciousness (DOC), including unresponsive wakefulness syndrome (UWS) [1-3] and minimally conscious state (MCS) $[4,5]$. Currently, the boundary between UWS and MCS patients has been welldefined [3-5]. The main difference between UWS and MCS is whether there is definite evidence that patients have a certain ability to be aware of themselves and the outside world, which is present only in patients with MCS. Clinical evaluations of the level of consciousness in patients with prolonged DOC have been conducted mainly through bedside spontaneous and stimulating behavioral responses [6-8]. The level of arousal is reflected in the assessment of the patient's open eye, whereas awareness is mainly assessed based on the patient's perception of himself or herself and the external environment, i.e., the patient's non-reflexive behavior under stimulation or the evaluator's accidental discovery of the patient's nonreflexive behavior. UWS patients have clear characteristics of awakening without awareness [9]. There are spontaneous or stimulus-induced open-eye reactions, sleep-wake cycles, and spontaneous reflexes (such as grunts and yawns), but there is a complete lack of awareness of oneself or the environment in UWS patients $[8,10]$. That is, there is no clear evidence of awareness or directed response to external stimuli; however, the presence of repetitive non-reflexive behavioral responses suggests a transition to the MCS state. MCS patients can generally show some behavioral response characteristics related to consciousness $[4,11]$. In these patients, there is weak and fluctuating but definite behavioral evidence of a distinct sense of self or of the environment, such as the ability to visually track objects and the ability to understand verbal information and follow instructions. At the same time, MCS can be further divided into MCS plus (MCS+) and MCS minus (MCS-) subtypes according to the complexity of the behavioral response (such as the presence of language comprehension) [5]. Once patients can communicate functionally or can use functional objects, they are diagnosed with emergence from MCS (EMCS) [12, 13].

Due to the difficulty of performing bedside consciousness assessments of patients with prolonged DOC, the rate of misdiagnosis is very high [14]. Different diagnosis results are crucial for clinical treatment, nursing, and even affect the decision of life termination [7, 15, 16]. For example, the treatment of transcranial direct current stimulation may be more effective in MCS than in UWS patients [17]. MCS is probably associated with a better prognosis than UWS [10]. In addition, Boly et al. found that the perception of pain is preserved in MCS patients, which indicated that these patients may need analgesic treatment [18]. The development and use of the Coma Recovery Scale-Revised (CRS-R) has greatly reduced the rate of clinical misdiagnosis of prolonged DOC [19]. The scale measures the patient's auditory, visual, motor, oromotor, communication and arousal function to assess the patient's level of consciousness and is now the most reliable diagnostic tool for patients with prolonged DOC [20]. Previous studies have shown that a single CRS-R assessment can identify $41 \%$ MCS patients who had been misdiagnosed with UWS based on clinical consensus [21]. In addition, recent studies have shown similar results, with a misdiagnosis rate of $35.3 \%$ for clinical consensus [22]. To date, several versions of the CRS-R scale have been developed and validated [23-27]; however, due to the influence of patients' awakening or consciousness fluctuations, movement defects, aphasia, and other problems [28-30], a single standard CRS-R behavior evaluation still leads to a nonzero rate of misdiagnosis. Therefore, repeated behavior scale evaluations [31] and personalized item selection [32, 33] of the neurobehavioral-assessment instrument have been for consciousness evaluations of clinical patients in order to improve the reliability of diagnosis.

In recent years, the concept of prolonged DOC has been clinically wide spread [10, 34]; however, the CRS-R is still not often used in clinical practice but is mostly used by clinical psychologists and specialized researchers. In this study, the difference between clinicians' diagnoses and the diagnosis of a single CRS-R assessment was compared, and the proportion of misdiagnosis by clinical consensus compared with the assessment results of a repeated CRS$\mathrm{R}$ was analyzed.

\section{Methods}

\section{Patients}

Patients with prolonged brain injuries admitted by the neurology department and the neurological rehabilitation department were primarily enrolled. The inclusion criteria were as follows: (1) at least 16 years old, (2) 28 or more days elapsed after onset, and (3) no neuromuscular blockers or sedatives were used within $72 \mathrm{~h}$ of enrollment. The exclusion criteria were: (1) being in a coma, (2) presence of functional disorders caused by progressive mental diseases, (3) persistent seizures, and (4) unstable vital signs.

This study protocol was approved by the Ethics Committee of Hangzhou Normal University. Written informed consent was obtained from the guardians/next of kin of the patients who participated in this study.

\section{Data collection}

Patients with prolonged DOC during hospitalization were screened by clinicians, and the clinicians in charge determined the patients' consciousness according to behavior during hospitalization (including the Glasgow Coma Scale assessment and other physical examinations) and their 
own clinical experience to form a clinical-consensus diagnosis. Patients included those with UWS with no consciousness and MCS with minimal consciousness. Subsequently, at least two experienced clinical psychologists used the CRS-R to evaluate the neurological behavior of the enrolled patients in five or more assessments over the following week (once or twice a day). Each patient's diagnostic results and special behaviors were recorded. From the repeated evaluation results, the highest scoring diagnosis was selected as the final bedside behavior diagnosis. All patients with prolonged DOC were divided into UWS, MCS-, MCS+, and EMCS groups.

\section{Statistical analysis}

A statistical evaluation was performed for all demographic information. Number, percentage, median, and range were produced for categorical variables, and means and standard deviations (SD) were calculated for age, time since onset, and the score on the CRS-R scale.

A chi-square test (and Fisher exact test when necessary) was used to test for group differences in demographic characteristics (i.e., gender, etiology, age and injury time) on the proportion of misdiagnosis. A Mann-Whitney $\mathrm{U}$ test (Wilcoxon rank-sum test) was used to analyze the difference between the scores of the first and final diagnoses. The statistical significance was set at $p<0.05$.

\section{Results}

A total of 137 patients with prolonged DOC selected by their clinicians were included in the study, which took place between July 2017 and October 2019. Baseline patient characteristics (numbers, percentage, median, and range or mean \pm SD) are provided for all included research individuals (Table 1). There were 40 female patients (29.2\%) and 97 male patients (70.8\%). Sixty-nine patients had suffered traumatic brain injuries (TBI, caused by a violent blow or jolt to the head or body) (50.4\%), and 61 patients had suffered cerebrovascular accidents (CVA, hemorrhage caused, infarction and subarachnoid hemorrhage) (44.5\%), and 7 patients had suffered anoxic brain injuries (ABI) (5.1\%). The mean age was $51.88 \pm 13.93$ years (range 19 to 84 years). The mean time since onset was $5.58 \pm 4.32$ months (range 1 to 22 months), and 44 patients suffered from permanent DOC (32.1\%).

The mean score of the single CRS-R assessment was $7.93 \pm 4.3$ points (range 2 to 24 ), and the mean score of the final CRS- $R$ assessment was $8.87 \pm 4.32$ points (range 2 to 24), which was higher than the single assessment score $(U=7827.5, p=0.02)$.

Figure 1 shows the diagnostic process and results for all patients with prolonged DOC. Of the 137 patients with acquired brain injury enrolled, 48 were diagnosed by clinical consensus as MCS and 89 as UWS. After a
Table 1 Demographic characteristics and clinical data of patients with prolonged DOC

\begin{tabular}{lllll}
\hline Characteristics/Variables & $\boldsymbol{n}$ & $\%$ & Mean \pm SD & Median (range) \\
\hline Sex & & & & \\
Male & 97 & 70.8 & & \\
Female & 40 & 29.2 & & \\
Etiology & & & & \\
TBI & 69 & 50.4 & & \\
CVA & 61 & 44.5 & & \\
ABI & 7 & 5.1 & & \\
Age (years) & 137 & & $51.88 \pm 13.93$ & $52(19-84)$ \\
16-44 & 37 & & $34.41 \pm 6.9$ & $35(19-44)$ \\
$45-59$ & 57 & & $51.3 \pm 4.44$ & $51(45-59)$ \\
$\geq 60$ & 43 & & $67.7 \pm 5.95$ & $66(60-84)$ \\
Time post-onset (m) & & & & \\
Whole sample & 137 & & $5.58 \pm 4.32$ & $4(1-22)$ \\
Non-permanent & 93 & 67.9 & $3.92 \pm 2.45$ & $3(1-11.5)$ \\
Permanent & 44 & 32.1 & $9.1 \pm 5.23$ & $7(4-22)$ \\
CRS-R scores & & & & \\
Single assessment & 137 & & $7.93 \pm 4.3$ & $7(2-24)$ \\
Repeated assessment & 137 & $8.87 \pm 4.32$ & $8(2-24)$ \\
\hline
\end{tabular}

SD Standard deviation, DOC Disorders of consciousness, TBI Traumatic brain injury, CVA Cerebrovascular accident, $A B I$ Anoxic brain injury, $C R S-R$ Coma Recovery Scale-Revised, $n$ numbers, $m$ months

Permanent $=$ three months after postinjury (non-traumatic), 12 months after postinjury (traumatic)

single CRS-R evaluation, 62 were diagnosed with MCS, 8 with EMCS, and 67 with UWS. After repeated CRS-R evaluations, 73 were diagnosed with MCS, 9 with EMCS, and 55 with UWS.

It was also found that after a single CRS-R evaluation, 7 of the 48 patients with a diagnosis of MCS based on clinical consensus were diagnosed with EMCS $(7 / 48=14.6 \%)$, 40 with MCS $(40 / 48=83.3 \%)$, and 1 with UWS $(1 / 48=$ 2.1\%) (Table 2). After repeated CRS-R evaluations, 1 of the 40 patients diagnosed with MCS based on a single CRS-R assessment was diagnosed with EMCS $(1 / 40=2.5 \%)$ and 39 with MCS $(39 / 40=97.5 \%$, with 2 diagnoses revised from MCS- to MCS+). The diagnosis of 1 UWS was still UWS, and 7 EMCS were still diagnosed with EMCS. Among the 89 patients with clinical UWS, the diagnosis of 22 patients was improved to MCS $(22 / 89=24.7 \%)$ after a single CRS-R evaluation. One was improved to EMCS (1/ $89=1.1 \%$ ), and 66 maintained the diagnosis of UWS (66/ $89=74.2 \%)$. After repeated CRS-R evaluations, 12 of the 66 patients diagnosed with UWS based on a single CRS-R assessment were diagnosed with MCS $(12 / 66=18.2 \%)$, while 54 were diagnosed with UWS $(54 / 66=81.8 \%)$, while 22 MCS were still diagnosed with MCS $(22 / 22=100 \%$, but 1 diagnosis was improved from MCS- to MCS+), 1 EMCS was still diagnosed with EMCS. 


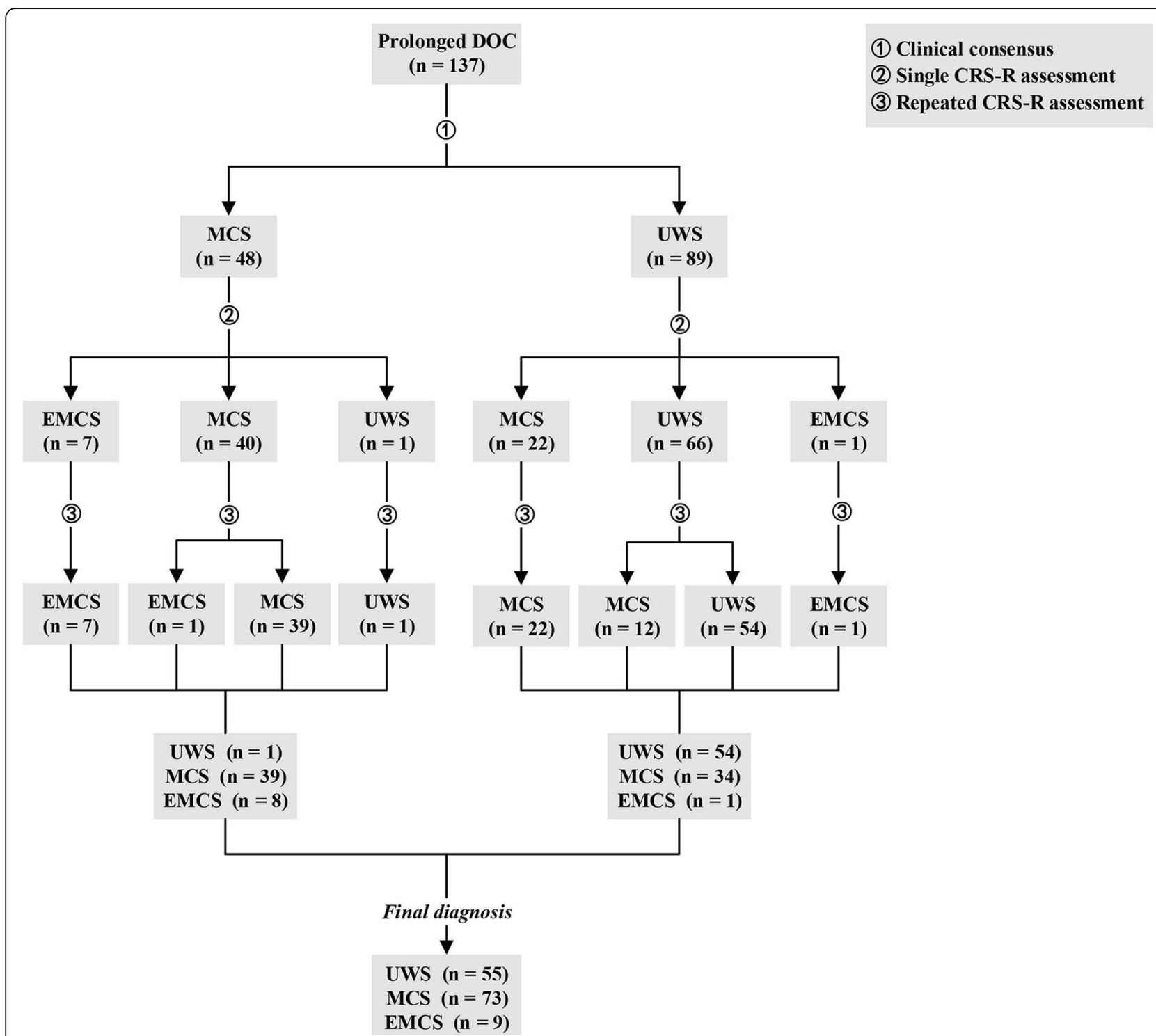

Fig. 1 Flowchart of participants through the study. Of the 137 patients with prolonged DOC enrolled, 48 were diagnosed by clinical consensus as MCS and 89 as UWS. After a single CRS-R evaluation, 62 were diagnosed with MCS, 8 with EMCS, and 67 with UWS. After repeated CRS-R evaluations, 73 were diagnosed with MCS, 9 with EMCS, and 55 with UWS. DOC= disorders of consciousness; UWS = unresponsive wakefulness syndrome; MCS = minimally conscious state; $E M C S=$ emergence from minimally conscious state; $n=$ numbers

Overall, 24.7\% of MCS patients were misdiagnosed with UWS based on clinical consensus after single evaluations (22/89). The proportion of EMCS being misdiagnosed with MCS was $14.6 \%(7 / 48=14.6 \%)$. After repeated evaluations, $38.2 \%$ of MCS patients were misdiagnosed with UWS based on clinical consensus (34/89). The proportion of EMCS misdiagnosed with MCS was $16.7 \%(8 / 48=16.7 \%)$ (Table 2). Table 2 also shows the rate of misdiagnosis by clinical consensus for different demographic variables, including frequency and proportion of misdiagnosis. It was found that there was no significant difference in the proportion of misdiagnosis among different genders, etiologies, age groups, and time since onset $(p>0.05)$.
Figure 2 shows the number of patients with CRS-R subscales representing signs of consciousness when diagnosed with MCS or EMCS after a single assessment and after repeated assessment. After a single CRS-R assessment, among 22 patients diagnosed with MCS, 2 patients showed a sign of consciousness on the auditory subscale (9.1\%), 16 patients on the visual subscale (72.7\%), 12 patients on the motor subscale (54.5\%), 0 patients on the oromotor/verbal subscale (0\%), and 1 patient on the communication subscale (4.5\%). After repeated CRS-R assessments of 34 patients with a diagnosis of MCS, 4 patients showed signs of consciousness on the auditory subscale (11.8\%), 26 on the visual subscale (76.5\%), 16 on the motor subscale 
Table 2 Numbers of misdiagnosis in relation to demographic profiles of patients with prolonged DOC in different diagnosis settings

\begin{tabular}{|c|c|c|c|c|c|c|}
\hline & \multicolumn{2}{|c|}{ Clinical consensus } & \multicolumn{2}{|c|}{ Single assessment } & \multicolumn{2}{|c|}{ Repeated assessment } \\
\hline & UWS, $n$ & MCS, $n$ & $\mathrm{MCS}, n(\%)^{\mathrm{a}}$ & EMCS, $n(\%)^{b}$ & MCS, $n(\%)^{a}$ & EMCS, $n(\%)^{b}$ \\
\hline \multicolumn{7}{|l|}{ Sex } \\
\hline Male & 65 & 32 & $18(27.7)$ & $4(12.5)$ & $28(43.1)$ & $4(12.5)$ \\
\hline Female & 24 & 16 & $4(16.7)$ & $3(18.8)$ & $6(25)$ & $4(25)$ \\
\hline$p$ value & & & $>0.05$ & $>0.05$ & $>0.05$ & $>0.05$ \\
\hline \multicolumn{7}{|l|}{ Etiology } \\
\hline $\mathrm{TB} \mid$ & 44 & 25 & $11(25)$ & $4(16)$ & 17 (38.6) & $5(20)$ \\
\hline CVA & 38 & 23 & $11(28.9)$ & $3(13.0)$ & $1743.6)$ & $3(13.0)$ \\
\hline$A B \mid$ & 7 & 0 & 0 & 0 & 0 & 0 \\
\hline$p$ value & & & $>0.05$ & $>0.05$ & $>0.05$ & $>0.05$ \\
\hline \multicolumn{7}{|l|}{ Age (years) } \\
\hline $16-44$ & 27 & 10 & $6(22.2)$ & $1(10)$ & $11(41)$ & $1(10)$ \\
\hline $45-59$ & 37 & 20 & $12(32.4)$ & $4(20)$ & $16(43.2)$ & $5(25)$ \\
\hline$\geq 60$ & 25 & 18 & $4(16)$ & $2(11.1)$ & $7(28)$ & $2(11.1)$ \\
\hline$p$ value & & & $>0.05$ & $>0.05$ & $>0.05$ & $>0.05$ \\
\hline \multicolumn{7}{|l|}{ Time post-onset } \\
\hline Permanent & 27 & 17 & $6(22.2)$ & $1(5.9)$ & $9(33.3)$ & $1(5.9)$ \\
\hline Non-permanent & 62 & 31 & $16(25.8)$ & $6(19.4)$ & $25(40.3)$ & $7(22.6)$ \\
\hline$p$ value & & & $>0.05$ & $>0.05$ & $>0.05$ & $>0.05$ \\
\hline Total & 89 & 48 & $22(24.7)$ & $7(14.6)$ & $34(38.2)$ & $8(16.7)$ \\
\hline
\end{tabular}

${ }^{a}$ Numbers of MCS patients were misdiagnosed as UWS; ${ }^{b}$ Numbers of EMCS patients were misdiagnosed as MCS

DOC Disorders of consciousness, UWS Unresponsive wakefulness syndrome, MCS Minimally conscious state, EMCS Emergence from minimally conscious state, TBI Traumatic brain injury, CVA Cerebrovascular accident, $A B I$ Anoxic brain injury, $X^{2}$ Chi-square, $n$ numbers

(47.1\%), 0 on the oromotor/verbal subscale (0\%), 1 on the communication subscale (2.9\%). Of the 7 patients diagnosed with EMCS after a single assessment, 4 (57.1\%) scored on the motor subscale, and 7 (100\%) scored on the communication subscale. After repeated evaluations, 5 (55.6\%) of the 9 patients diagnosed with EMCS scored on the motor subscale, and 8 (88.9\%) scored on the communication subscale.

\section{Discussion}

The main objective of this study was to investigate the misdiagnosis rates of clinical consensus compared to those of repeated behavior-scale assessments. After the single CRS-R behavior evaluation, it was found that the proportion of misdiagnosis of clinical MCS was 24.7\%, while the repeated CRS-R evaluation results showed that the proportion of misdiagnosis of clinical MCS was $38.2 \%$. A total of $16.7 \%$ of EMCS patients was misdiagnosed with MCS, and $1.1 \%$ of EMCS patients was misdiagnosed with UWS.

For the evaluation of the consciousness level of patients with prolonged DOC, many previous studies had compared the diagnostic results of the standard CRS-R scale with other scales, and it was been found that the CRS-R scale had the highest sensitivity in detecting the consciousness of patients with MCS $[35,36]$. When the CRS-R scale was used, it was found that many patients with a clinical-consensus diagnosis of unconscious actually remained minimally conscious. Schnakers et al. found that $41 \%$ of patients with a clinical-consensus diagnosis of UWS was actually found to suffer from MCS after an evaluation using the standard CRS-R behavior scale, whereas the clinical consensus was that $10 \%$ of patients with MCS were actually higher conscious EMCS (fully conscious) [21]. A recent study on repeated CRS-R behavior assessments showed that the clinical consensus still had a 33\% misdiagnosis rate when diagnosing MCS patients [22]. This also supports the results of the current study. It was found that repeated behavioral assessments could identify $38.2 \%$ MCS patients. Moreover, the proportion of misdiagnosis of EMCS with full consciousness was $16.7 \%$. When the evaluation results of the single CRS-R scale were compared with the clinical consensus, it was found that $24.7 \%$ of patients were misdiagnosed with MCS by clinical consensus, which was significantly lower than the $41 \%$ found in previous studies on the proportion of misdiagnosis; however, the $14.6 \%$ misdiagnosis rate of EMCS was similar to the $10 \%$ rate in a previous study [21]. With the continuous progress in the field of prolonged DOC, 
A Single assessment

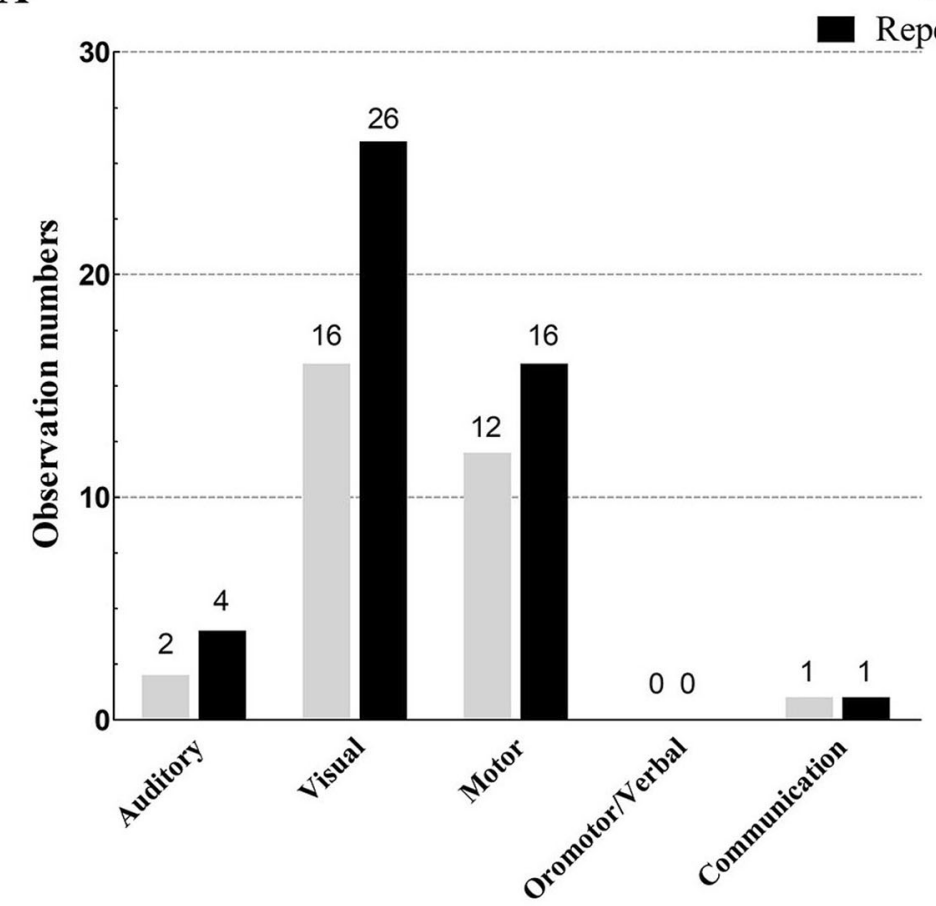

CRS-R items

B

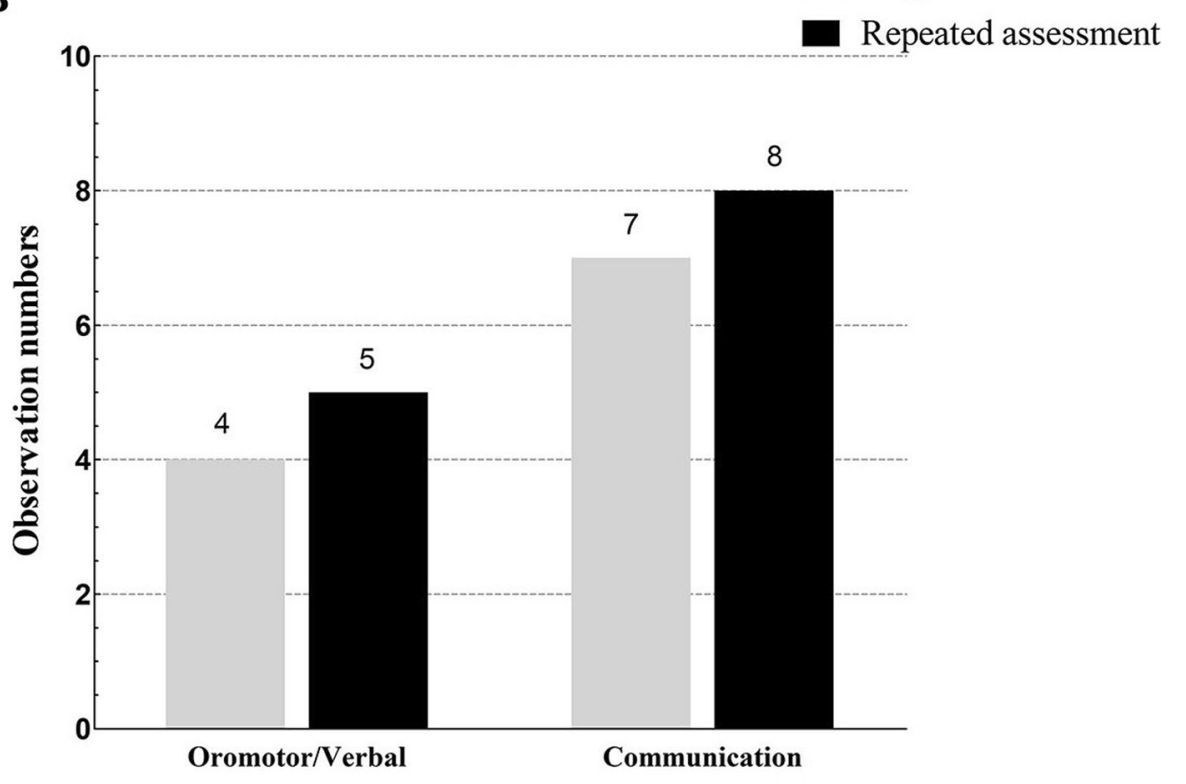

\section{CRS-R items}

Fig. 2 The number of CRS-R subscales representing signs of consciousness when diagnosed with MCS or EMCS after a single CRS-R assessment and after repeated CRS-R assessments. $\mathbf{a}$. In these terms, Auditory $=3-4$ OR Visual $=2-5$ OR Motor $=3-5$ OR OromotorNerbal $=3$ OR Communication $=1$, indicating that the patient has signs of consciousness and is diagnosed as MCS. Of the patients with a clinical consensus diagnosis of UWS, 22 were diagnosed with MCS after a single CRS-R assessment. After repeated CRS-R assessments, 34 patients were diagnosed with MCS. $\mathbf{b}$. In these terms, Motor $=6$ OR Communication $=2$, indicating that the patient has signs of full consciousness and is diagnosed as EMCS. Of the patients with a clinical consensus diagnosis of MCS and UWS, 8 were diagnosed with EMCS after a single CRS-R assessment. After repeated CRS-R assessments, 9 patients were diagnosed with EMCS. CRS-R=Coma Recovery Scale-Revised; MCS = minimally conscious state; $E M C S=$ emergence from minimally conscious state 
clinicians have gained a deeper understanding of this concept. This may be the reason for the significant difference in misdiagnosis rates over the past 10 years. In addition, the difference between the results of single assessments and repeated assessments emphasizes that the fluctuations of patients' responsiveness have an effect on neuro-behavioral assessments, and also emphasizes the importance of repeated assessments in clinical diagnosis.

The degree to which the patient's demographic factors lead to clinical misdiagnosis was analyzed, and it was found that differences in gender, etiology, age groups and postinjury time were not factors in clinical-consensus misdiagnosis. It is highly likely that clinical workers are highly dependent on the patients' bedside behaviors in the patients' daily management and may not be using systematic and standardized behavioral-assessment tools to diagnose awareness. In addition, it was found that the Glasgow Coma Scale (GCS) was widely used for almost all patients admitted to the hospital, while a previous study showed that that scale was not appropriate for assessing a patient's level of consciousness [23]. Unlike the GCS scale, the CRS-R scale has very clear MCS diagnostic criteria, and the evaluation of consciousness from various angles can be used to more sensitively diagnose the consciousness level of patients, which greatly reduces the misdiagnosis of patients with prolonged DOC. Therefore, the use of standardized CRS-R assessment tools is particularly important for the detection of clinical patients' level of consciousness and patient management.

During the implementation of the standardized CRS-R scale, many studies found that the standard CRS-R scale still lead to some misdiagnoses. Cheng and Gosseries et al. found that the patient's name was more suitable stimulus for the detection of auditory localization than other sound stimuli [37]. Vanhaudenhuys et al. also found that the best way to check visual pursuit in MCS patients was to use a moving mirror rather than a moving person or object [38, 39]. Therefore, the application of personally related visual and auditory stimulation can better reduce the proportion of misdiagnosis of patients compared with natural stimulation [33]. In addition, when the CRS-R was used to evaluate the use of functional objects for MCS patients, the use of personalized objects more frequently elicited responses from patients, thereby identifying misdiagnosed EMCS [32]. For this study, repeated CRS-R behavior assessments were employed, during which family members or caregivers were asked about patients' items of interest. To better elicit the patients' responses, a variety of different stimuli were selected according to the patients' performance during the evaluation process, namely natural stimuli and personally related stimuli. It was found that when patients were diagnosed with MCS based on the first behavior evaluation, most showed signs of consciousness on the visual (72.7\%) and motor (54.5\%) subscales, and few showed signs of consciousness on the auditory (9.1\%) and communication (4.5\%) subscales. After repeated evaluations, 10 patients showed signs of consciousness on the visual subscale, 4 patients on the motor subscale, and 2 patients in the auditory subscale. This was most likely due to fluctuations in the patients' levels of arousal or consciousness and due to the use of personally associated stimuli.

It was also found that, for the vast majority of patients diagnosed with MCS, the items eliciting signs of consciousness were mainly related to the visual subscale (visual pursuit and visual fixation), the motor subscale (automatic motor response and localization to noxious stimulation), and the auditory subscale (reproducible movement to command). These results were confirmed by a previous study [40], but with the difference that the most sensitive item in the present study was the visual subscale, while the most sensitive item in the previous study was the reproducible movement to command items on the auditory subscale.

Based on these results, it was found that the clinical consensus had a higher proportion of misdiagnosis, especially compared to repeated CRS-R scales. This highlights the importance of the CRS-R scale in the assessment of patient consciousness. It is suggested that, for patient daily management, clinicians should at least evaluate visual pursuit and visual fixation for the visual subscale, automatic motor response and localization to noxious stimulation for the motor subscale, and reproducible movement to command for the auditory subscale when assessing patients' levels of consciousness. This can greatly reduce misdiagnosis, although, for patients with prolonged DOC, bedside neurobehavioral assessment has some limitations, and neuroimaging is an important method for the diagnosis of consciousness [22]; however, a behavioral assessment is still the most direct and portable method and should be promoted in clinical practice.

The limitation of this study was that no neuroimaging methods were used to evaluate the enrolled patients with prolonged DOC. Because the CRS-R scale still produces some false negatives, in the future, behavioral assessments combined with neuroimaging should be used to truly understand misdiagnosis by clinical consensus.

\section{Conclusions}

Although many studies have emphasized the importance of diagnosis, this study showed that the current rate of misdiagnosis by clinical consensus is still relatively high. Misdiagnosis greatly affects the clinical management of patients with prolonged DOC. Therefore, clinicians should be aware of the importance of bedside CRS-R 
behavior assessments and should apply the CRS-R scale to their daily procedures. Choosing stimuli that are relevant to the patient and evaluating them on a standard scale can better identify the patient's covert consciousness. For a rapid evaluation of patients, visual pursuit and visual fixation for the visual subscale, automatic motor response and localization to noxious stimulation for the motor subscale, and reproducible movement to command for the auditory subscale are recommended.

\section{Abbreviations}

DOC: Disorders of Consciousness; UWS: Unresponsive Wakefulness

Syndrome; MCS: Minimally Conscious State; MCS+: Minimally Conscious State Plus; MCS-: Minimally Conscious State Minus; EMCS: Emergence from Minimally Conscious State; CRS-R: Coma Recovery Scale-Revised;

TBI: Traumatic Brain Injury; CVA: Cerebrovascular Accident; ABI: Anoxic Brain Injury

\section{Acknowledgements}

The authors thank the patients and their families, the management of clinicians and the assistance of Wangshan Huang in some data collection.

\section{Authors' contributions}

JW, ZH, ZS and XH collected data and managed the patients; JW performed data analyses; JW, HD and SL designed the study; JW wrote the paper. HD revised the manuscript for important intellectual content. All authors discussed the results and commented on the manuscript. All authors read and approved the final manuscript.

\section{Funding}

This study was supported by the National Natural Science Foundation of China (81471100, 811247008), the National High Technology Research and Development Program of China (2015AA020514), the National Natural Science Foundation of China (81920108023), Hangzhou Normal University (2018PYXML007), Zhejiang Province Chinese Medicine Science and Technology Program Project (2018ZB101), Zhejiang Basic Public Interest Research Program Project (LGF20H090017), the European Union's Horizon 2020 Framework Program for Research and Innovation under the Specific Grant Agreement (Human Brain Project SGA2, 785907), the fund Generet, the King Baudouin Foundation, and the DOCMA project (EU-H2020-MSCA-RISE778234). The funders had no role in study design, data collection and analysis, interpretation of data, decision to publish or preparation of the manuscript.

\section{Availability of data and materials}

The datasets used and/or analyzed during the current study are available from the corresponding author on reasonable request.

\section{Ethics approval and consent to participate}

This study protocol was approved by the Ethics Committee of Hangzhou Normal University. Written informed consent was obtained from the guardians/next of kin of the patients who participated in this study.

\section{Consent for publication}

Not applicable.

\section{Competing interests}

The authors declare that they have no competing interests.

\section{Author details}

${ }^{1}$ International Unresponsive Wakefulness Syndrome and Consciousness Science Institute, Hangzhou Normal University, Hangzhou 310036, China. ${ }^{2}$ Rehabilitation Center for Brain Damage, Wujing Hospital of Hangzhou City, Hangzhou, China. ${ }^{3}$ Coma Science Group, GIGA Consciousness, University and University Hospital of Liège, Liège, Belgium.
Received: 7 November 2019 Accepted: 8 September 2020

Published online: 12 September 2020

\section{References}

1. van Erp WS, Lavrijsen JC, van de Laar FA, Vos PE, Laureys S, Koopmans RT. The vegetative state/unresponsive wakefulness syndrome: a systematic review of prevalence studies. Eur J Neurol. 2014;21(11):1361-8. https://doi. org/10.1111/ene.12483.

2. Laureys S, Celesia GG, Cohadon F, Lavrijsen J, Leon-Carrion J, Sannita WG, et al. Unresponsive wakefulness syndrome: a new name for the vegetative state or apallic syndrome. BMC Med. 2010;8:68. https://doi.org/10.1186/ 1741-7015-8-68

3. Monti MM, Laureys S, Owen AM. The vegetative state. BMJ. 2010;341:c3765. https://doi.org/10.1136/bmj.c3765.

4. Giacino JT, Ashwal S, Childs N, Cranford R, Jennett B, Katz DI, et al. The minimally conscious state: definition and diagnostic criteria. Neurology. 2002;59(9):1473-4

5. Bruno MA, Vanhaudenhuyse A, Thibaut A, Moonen G, Laureys S. From unresponsive wakefulness to minimally conscious PLUS and functional locked-in syndromes: recent advances in our understanding of disorders of consciousness. J Neurol. 2011;258(7):1373-84. https://doi.org/10.1007/ s00415-011-6114-x.

6. Gosseries O, Zasler ND, Laureys S. Recent advances in disorders of consciousness: focus on the diagnosis. Brain Inj. 2014;28(9):1141-50. https:// doi.org/10.3109/02699052.2014.920522.

7. Hirschberg R, Giacino JT. The vegetative and minimally conscious states: diagnosis, prognosis and treatment. Neurol Clin. 2011;29(4):773-86. https:// doi.org/10.1016/j.ncl.2011.07.009.

8. Gosseries O, Di H, Laureys S, Boly M. Measuring consciousness in severely damaged brains. Annu Rev Neurosci. 2014:37:457-78. https://doi.org/10. 1146/annurev-neuro-062012-170339.

9. Ashwal S, Cranford R. Medical aspects of the persistent vegetative state--a correction. The multi-society task force on PVS. N Engl J Med. 1995:333(2): 130. https://doi.org/10.1056/NEJM199507133330217.

10. Giacino JT, Katz DI, Schiff ND, Whyte J, Ashman EJ, Ashwal S, et al. Comprehensive systematic review update summary: disorders of consciousness: report of the guideline development, dissemination, and implementation Subcommittee of the American Academy of neurology; the American congress of rehabilitation medicine; and the National Institute on Disability, Independent Living, and Rehabilitation Research. Neurology. 2018; 91(10):461-70. https://doi.org/10.1212/WNL.0000000000005928.

11. Giacino JT. The vegetative and minimally conscious states: consensus-based criteria for establishing diagnosis and prognosis. NeuroRehabilitation. 2004; 19(4):293-8

12. Machado C, Perez-Nellar J, Rodriguez R, Scherle C, Korein J. Emergence from minimally conscious state: insights from evaluation of posttraumatic confusion. Neurology. 2010;74(14):1156-7. https://doi.org/10.1212/WNL. 0b013e3181d5df0d.

13. Nakase-Richardson R, Yablon SA, Sherer M, Evans CC, Nick TG. Serial yes/no reliability after traumatic brain injury: implications regarding the operational criteria for emergence from the minimally conscious state. J Neurol Neurosurg Psychiatry. 2008;79(2):216-8. https://doi.org/10.1136/jnnp.2007. 127795

14. Childs NL, Mercer WN, Childs HW. Accuracy of diagnosis of persistent vegetative state. Neurology. 1993;43(8):1465-7.

15. Andrews K. Medical decision making in the vegetative state: withdrawal of nutrition and hydration. NeuroRehabilitation. 2004;19(4):299-304.

16. Fins JJ, Bernat $\mathrm{J}$. Ethical, palliative, and policy considerations in disorders of consciousness. Neurology. 2018:91(10):471-5. https://doi.org/10.1212/WNL. 0000000000005927.

17. Thibaut A, Bruno MA, Ledoux D, Demertzi A, Laureys S. tDCS in patients with disorders of consciousness: sham-controlled randomized double-blind study. Neurology. 2014;82(13):1112-8. https://doi.org/10.1212/WNL. 0000000000000260

18. Boly M, Faymonville ME, Schnakers C, Peigneux P, Lambermont B, Phillips C, et al. Perception of pain in the minimally conscious state with PET activation: an observational study. Lancet Neurol. 2008;7(11):1013-20. https://doi.org/10.1016/S1474-4422(08)70219-9.

19. Giacino JT, Kalmar K, Whyte J. The JFK coma recovery scale-revised: measurement characteristics and diagnostic utility. Arch Phys Med Rehabil. 2004;85(12):2020-9. https://doi.org/10.1016/j.apmr.2004.02.033. 
20. Giacino JT, Schnakers C, Rodriguez-Moreno D, Kalmar K, Schiff N, Hirsch J. Behavioral assessment in patients with disorders of consciousness: gold standard or fool's gold? Prog Brain Res. 2009;177:33-48. https://doi.org/10. 1016/S0079-6123(09)17704-X.

21. Schnakers C, Vanhaudenhuyse A, Giacino J, Ventura M, Boly M, Majerus S, et al. Diagnostic accuracy of the vegetative and minimally conscious state: clinical consensus versus standardized neurobehavioral assessment. BMC Neurol. 2009;9(1):35. https://doi.org/10.1186/1471-2377-9-35.

22. Stender J, Gosseries O, Bruno M-A, Charland-Verville V, Vanhaudenhuyse A Demertzi A, et al. Diagnostic precision of PET imaging and functional MRI in disorders of consciousness: a clinical validation study. Lancet. 2014; 384(9942):514-22. https://doi.org/10.1016/s0140-6736(14)60042-8.

23. Zhang Y, Wang J, Schnakers $C$, He M, Luo H, Cheng L, et al. Validation of the Chinese version of the coma recovery scale-revised (CRS-R). Brain Inj. 2019;33(4):529-33. https://doi.org/10.1080/02699052.2019.1566832.

24. Di H, He M, Zhang Y, Cheng L, Wang F, Nie $Y$, et al. Chinese translation of the coma recovery scale-revised. Brain Inj. 2017;31(3):363-5. https://doi.org/ 10.1080/02699052.2016.1255780.

25. Binder M, Gorska U, Wojcik-Krzemien A, Gociewicz K. A validation of the polish version of the coma recovery scale-revised (CRSR). Brain Inj. 2018; 32(2):242-6. https://doi.org/10.1080/02699052.2017.1406991

26. Tamashiro M, Rivas ME, Ron M, Salierno F, Dalera M, Olmos L. A Spanish validation of the coma recovery scale-revised (CRS-R). Brain Inj. 2014;28(1314):1744-7. https://doi.org/10.3109/02699052.2014.947621.

27. Mochalova E, Legostaeva L, Zimin A, Sergeev D, Domashenko M, Samorukov $V$, et al. A Russian validation study of the coma recovery scalerevised (CRS-R); 2018. https://doi.org/10.1101/276881.

28. Cortese MD, Riganello F, Arcuri F, Pugliese ME, Lucca LF, Dolce G, et al. Coma recovery scale-r: variability in the disorder of consciousness. BMC Neurol. 2015;15:186. https://doi.org/10.1186/s12883-015-0455-5.

29. Schnakers $C$. Clinical assessment of patients with disorders of consciousness. Arch Ital Biol. 2012;150(2-3):36-43.

30. Kotchoubey B, Vogel D, Lang S, Muller F. What kind of consciousness is minimal? Brain Inj. 2014;28(9):1156-63. https://doi.org/10.3109/02699052. 2014.920523.

31. Wannez S, Heine L, Thonnard M, Gosseries O, Laureys S. Coma science group c: the repetition of behavioral assessments in diagnosis of disorders of consciousness. Ann Neurol. 2017;81(6):883-9. https://doi. org/10.1002/ana.24962.

32. Sun $Y$, Wang J, Heine L, Huang W, Wang J, Hu N, et al. Personalized objects can optimize the diagnosis of EMCS in the assessment of functional object use in the CRS-R: a double blind, randomized clinical trial. BMC Neurol. 2018;18(1):38. https://doi.org/10.1186/s12883-018-1040-5.

33. Stenberg J, Godbolt AK, Moller MC. The value of incorporating personally relevant stimuli into consciousness assessment with the coma recovery scale - revised: a pilot study. J Rehabil Med. 2018;50(3):253. https://doi.org/ 10.2340/16501977-2309.

34. Giacino JT, Katz DI, Schiff ND, Whyte J, Ashman EJ, Ashwal S, et al. Practice guideline update recommendations summary: disorders of consciousness: report of the guideline development, dissemination, and implementation Subcommittee of the American Academy of neurology; the American congress of rehabilitation medicine; and the National Institute on Disability, Independent Living, and Rehabilitation Research. Neurology. 2018;91(10): 450-60. https://doi.org/10.1212/WNL.0000000000005926.

35. Bodien YG, Carlowicz CA, Chatelle C, Giacino JT. Sensitivity and specificity of the coma recovery scale--revised Total score in detection of conscious awareness. Arch Phys Med Rehabil. 2016;97(3):490-2e1. https://doi.org/10. 1016/j.apmr.2015.08.422.

36. Schnakers C, Majerus S, Giacino J, Vanhaudenhuyse A, Bruno MA, Boly M, et al. A French validation study of the coma recovery scale-revised (CRS-R) Brain Inj. 2008;22(10):786-92. https://doi.org/10.1080/02699050802403557.

37. Cheng L, Gosseries O, Ying L, Hu X, Yu D, Gao H, et al. Assessment of localisation to auditory stimulation in post-comatose states: use the patient's own name. BMC Neurol. 2013;13:27. https://doi.org/10.1186/14712377-13-27.

38. Vanhaudenhuyse A, Schnakers C, Bredart S, Laureys S. Assessment of visual pursuit in post-comatose states: use a mirror. J Neurol Neurosur Ps. 2008; 79(2):223. https://doi.org/10.1136/Jnnp.2007.121624.

39. Wannez S, Vanhaudenhuyse A, Laureys S, Bredart S. Mirror efficiency in the assessment of visual pursuit in patients in minimally conscious state. Brain Inj. 2017;31(11):1429-35. https://doi.org/10.1080/02699052.2017.1376755.
40. Wannez S, Gosseries O, Azzolini D, Martial C, Cassol H, Aubinet C, et al. Prevalence of coma-recovery scale-revised signs of consciousness in patients in minimally conscious state. Neuropsychol Rehabil. 2017;28(8): 1350. https://doi.org/10.1080/09602011.2017.1310656.

\section{Publisher's Note}

Springer Nature remains neutral with regard to jurisdictional claims in published maps and institutional affiliations.

\section{Ready to submit your research? Choose BMC and benefit from:}

- fast, convenient online submission

- thorough peer review by experienced researchers in your field

- rapid publication on acceptance

- support for research data, including large and complex data types

- gold Open Access which fosters wider collaboration and increased citations

- maximum visibility for your research: over $100 \mathrm{M}$ website views per year

At BMC, research is always in progress.

Learn more biomedcentral.com/submissions 